\title{
Traceability System of Pig-Raising Process and Quality Safety on 3G
}

\author{
Benhai Xiong ${ }^{1,2,}$, Qingyao Luo ${ }^{1,2}$, Liang Yang ${ }^{1,2}$, and Jiayi Pan ${ }^{1,2}$ \\ ${ }^{1}$ Institute of Animal Science, Chinese Academy of Agricultural Sciences, \\ Beijing 100193, China \\ ${ }^{2}$ Satte Key Laboratory of Animal Nutrition, Beijing 100193, China
}

\begin{abstract}
In view of existed not flexibility and low efficiency in establishing feeding file of large-scale farms or farmer farms of pigs, by adopting intelligent PDA or mobile phone as application platform, combining with .Net 2005 language and SQL Server 2005 CE database as well as TD-SCDMA wireless wide band communication linking Internet as data transmission method, this study suggested data criterions on feeding process information collection of pigs, and developed a mobile PDA or phone system to track swine feeding process data, such as operators and main inputs, and to trace pork quality safety. The running of the system shows that it realized all kinds of data collecting and wireless submission including ear tag wearing and movements, immunity events, feeds and veterinary drugs used as well as casual inspection data, and also achieved remote data maintaining for pig's feeding files and deepness inquiry to pork quality. The system not only makes up a deficiency from table data recording system for feeding file setting of a large-scale swine farm, but also is a kind of effective solution for farmer farm to set up swine feeding files. Furthermore, the system is a kind of mobile and convenient supervising tool to service official veterinarian to carry out their work. Finally, with the TDSCDMA technology prevalence and communication fee decrease, the system will take part in a important role in constructing Chinese pork quality safety traceability system.
\end{abstract}

Keywords: Intelligent PDA, 3G, Live pigs, Feeding files, Quality traceability.

\section{Introduction}

Since a case of the Bovine spongiform encephalopathy (BSE) occurred in Britain in 1986, zoonoses such as BSE, highly pathogenic avian influenza (HPAI) and food quality safety problems such as Sudan red powder, melamine milk and Clenbuterol pork happened occasionally and so have been paid wide attention[1]. The case of Shuanghui Clenbuterol pork[2], reported by the CCTV on March 15,2010, showed again great potential problems for the food safety and the importance of supervision and traceability of animal product quality. Early in this century, some developed countries and regions set up trade barriers such as technical regulations, standards and conformity assessment procedures on the advantage of science and technology,

\footnotetext{
Corresponding author.
} 
management and environmental protection and established new threshold for Chinese export, especially for animal product export. From 1 January 2002, the European Union (EU) legislation ((EC) No 178/2002) require that all products sold in shops must have traceability labels, including the country of birth, fattening, slaughter, slaughterhouse ID, segmentation packaging country, segmentation grant No, whether European Union membership is and so on. Canada began to construct traceability system for individual identification, move and premises identification about cattle, sheep and swine as the earliest as 2001, developed the first traceability system in 2003, respectively published the first edition (Can-Trance standard) in 2003, and second edition of the agricultural traceability standard based on EAN.UCC information identification and bar code traceability system in 2006. These standards for all the food in Canada are not mandatory. U.S. introduced the biological invasion movement framework in 2002 and all foods sold in the United States, including US and other country food, must been registered in the U.S. food and drug administration (FDA). Importers and processors have the obligation to record information about their middle suppliers and buyers for 2 years at least, and must copy the records in order to accept the FDA investigation. Subsequently in 2007, FDA also announced food protection plan (FPP) to improve food security and strengthen traceability in the food processing and distribution processes[3,4,5].

In China, animal product quality traceability system began with animal epidemic prevention system led by the ministry of agriculture in 2002[3]. After the animal husbandry and law enacted in 2005, "the Administrative Rules on identification and rearing files for animal and poultry" was issued by the Ministry of Agriculture[6] and put in effect on July 1,2006. The rules proposed specific norms for identification and rearing files in pig-rearing link. Then, State council of China issued "the administrative regulations on pig slaughter"[7] on May 1, 2008 and took effect on August 1, 2008, which mainly provides legal base for supervising pigslaughtering link by commerce departments according to law.

$3 \mathrm{G}$ is able to provide high-speed data business and is the new generation mobile communication combining with wireless communication, multimedia communication technologies. TD-SCDMA is a 3G technology standard proposed by China based on international cooperation[8]. The technology convergence of wireless 3G network data transmission and international Internet system provide new technology means for expanding safety supervision and quality traceability for pig and products.

By the means of $3 \mathrm{G}$ technologies and PDA or mobile intelligent system, this study attempts to develop the mobile data collection and transmit system for main inputs in pig-producing link, and mobile terminal for government supervision and traceability enquiry, and provide technical reserves for exploring whole tracking and traceability solution in different pig-rearing models and network environments

\section{$2 \quad$ Materials and Methods}

\subsection{Research Object}

This study takes commercial pig-raising farms or household farmers as the research model, pig individual and pork end-product as the research object in order to study data collection solution in pig-raising link and traceability inquires on end product. 


\subsection{Individual Code and Ear Tag for Pig}

According to the administrative rule, a pig must have a unique logo code, which consists of 15 digit code. The first digit represents the category of animal, for example, 1 represents pig; Then the subsequent 6 digits represent administrative district code in where pig farms are located, corresponding with GB T2260-1999 [9]; the next eight digits from the 8 th to the 15 th is pig individual No in the same district.

\subsection{Data Standards for Pig-Raising Process}

In the pig-raising link, the required collection information includes responsible body information including pig-raising farm or farmer, pig individual identification, main inputs (feed, veterinary drugs, vaccine) and supervision test such as test results for Clenbuterol. As the space is limited, only part data standards listed in the study are respectively for responsible body (table 1), pig identification (table 2), vaccine (table 3), supervision and inspection (table 4). Mobile data collection in the raising link also based on the data standards.

Table 1. Base information for farm

\begin{tabular}{lllll}
\hline \multicolumn{1}{c}{ Name } & \multicolumn{1}{c}{ Field Name } & type & Length & IsNull \\
\hline Owner ID & FARM_ID & string & 20 & not \\
Owner & FARM_NAME & string & 50 & \\
Farm type & FARM_TYPE & string & 10 & \\
Address & FARM_ADDR & string & 100 & \\
legal representative & LEGAL_PERSON & string & 20 & \\
Record date & RECORD_DATE & date & 8 & \\
communication Address & ADDR & string & 100 & \\
Post code & POSTAL_CODE & string & 6 & \\
telephone & TEL & string & 20 & \\
fax & FAX & string & 20 & \\
\hline
\end{tabular}

Table 2. Individual data for swine

\begin{tabular}{lllll}
\hline \multicolumn{1}{c}{ Name } & \multicolumn{1}{c}{ Field Name } & \multicolumn{1}{c}{ type } & Length & IsNull \\
\hline Owner & FARM_NAME & string & 50 & not \\
Animal type & BREED_TYPE & string & 20 & not \\
Pigsty & PEN_No & number & 10 & \\
Use & PURPOSE & string & 10 & \\
Ear tag digit & EAG_No & number & 2 & \\
County & REGION & string & 40 & not \\
Ear tag ID & PIG_ID & string & 15 & \\
Buy date & BUY_DATE & date & 8 & \\
note & NOTE & string & 50 & \\
\hline
\end{tabular}

Table 3. Data of used vaccine

\begin{tabular}{lllll}
\hline \multicolumn{1}{c}{ Name } & \multicolumn{1}{c}{ Field Name } & type & Length & IsNull \\
\hline Ear tag ID & PIG_ID & string & 15 & not \\
Vaccine name & VACCINE_NAME & string & 50 & not \\
source & VACCINE & string & 50 & \\
& SOURCE & & & \\
batch & VACCINE_BATCH & string & 50 & \\
method & IMMUN_METHOD & string & 50 & \\
Beginning date & IMMUN_DATE & date & 8 & \\
End date & IMMUN_DATE & date & 8 & \\
person & IMMUN_PERSON & string & 10 & \\
note & NOTE & string & 50 & \\
\hline
\end{tabular}


Table 4. Data of supervision

\begin{tabular}{lllll}
\hline \multicolumn{1}{c}{ Name } & \multicolumn{1}{c}{ Field Name } & type & Length & IsNull \\
\hline Ear tag ID & PIG_ID & string & 15 & Not \\
No & CHECH_ID & string & 20 & \\
item & CHECH_ITEM & string & 30 & Not \\
Method & CHECH_METHOD & string & 20 & \\
Result & CHECH_RESULT & string & 10 & \multirow{2}{*}{ Not } \\
date & CHECK_DATE & date & 20 & \\
Unit & CHECK_UNIT & string & 50 & \\
Person & CHECH_PERSON & string & 20 & \\
note & NOTE & string & 50 & \\
\hline
\end{tabular}

\subsection{Development Environment}

System development adopts Microsoft Visual Studio, Windows mobile 6.0 SDK, SQL mobile 2005, Visual c \#, Microsoft ActiveSync 4.5[10,11]. A PDA or smart phone collect, submit the collected data to the Tianjin pork quality traceability central database constructed by XiongBenHai (2009)[12], or modify and query uploaded data remotely.

\subsection{Technical Route of System Development}

As shown in Fig 1, system models contain user management model solving user extent to different data use, raising files model including collection and transmission of data, supervision and inspection model for official vet to treat test results for hormone, sulfonamides and heavy metal residues for marketing pigs and for government easily to know sampling supervision results, tracing inquiry model to provide different levels of query service for government supervision department and consumers.

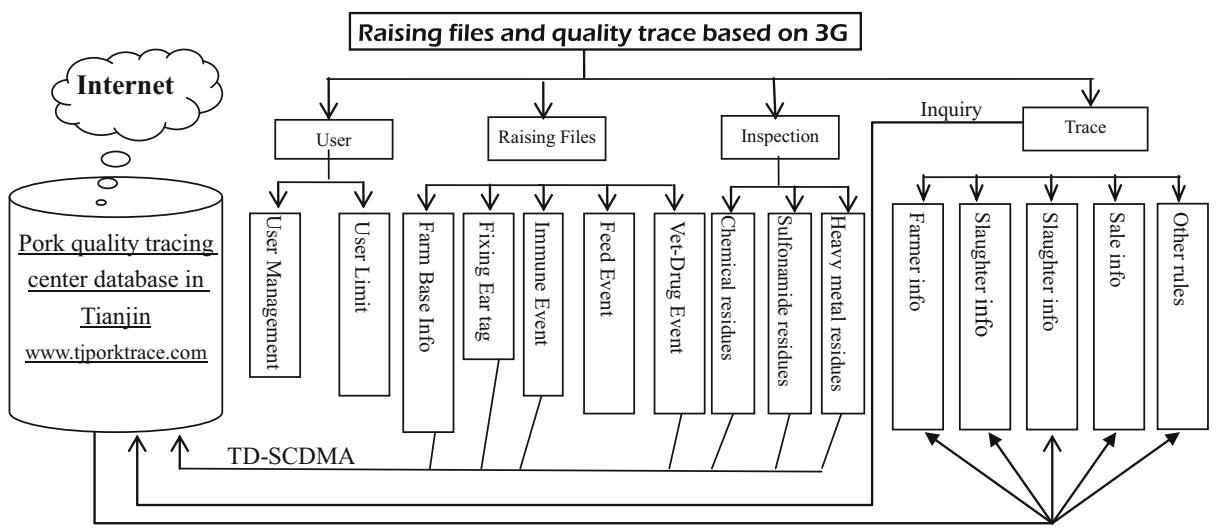

Fig. 1. Function structure of embed system on pig feeding process data collection and final product quality inquiry

\section{Results and Analysis}

According to pig identification code, data collection standards, hardware and software development environments and technology framework of system function design suggested from 2.1 to 2.5 , mobile construction of pig-raising files and traceability inquiry system based on intelligent PDA or phone is developed. Main results are as follows: 


\subsection{Collection of Pig Individual Identification}

Fig 2 showed the running interface for fixing ear-tag, 15-digit code can be not only manually typed in and also scanned by PDA in batches. Considering PDA's memory capacity, the max number of reading or inputting ear-tag is 20 every operation. Collecting data can save in the mobile client or IC card in .txt file format in order to subsequent data treatment, also synchronize to PC or directly submit to remote pork quality traceability center database by GPRS (2G) or TD-SCDMA(3G).

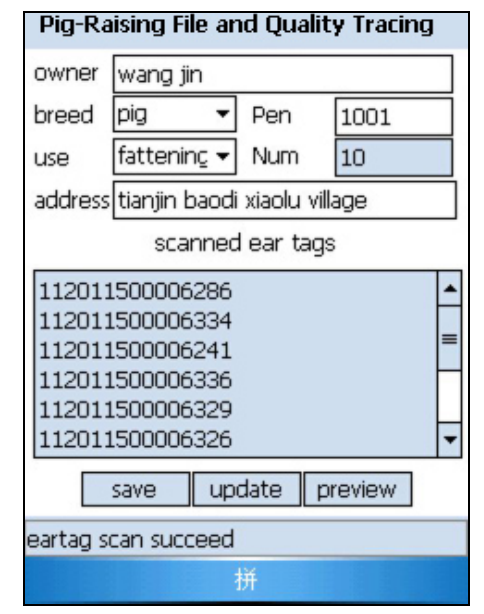

Fig. 2. Tag wearing, data collection and submission for pig

\subsection{Collection of Pig Immunity Event}

Fig 3 shows treatment model for pig immune event. After ear tag number is inputted or scanned, immune information is inputted. Of which used vaccine information is stored in the system database and can selected in the running period and reduced cumbersome text-entry. Inputting data generally submits to remote center database.
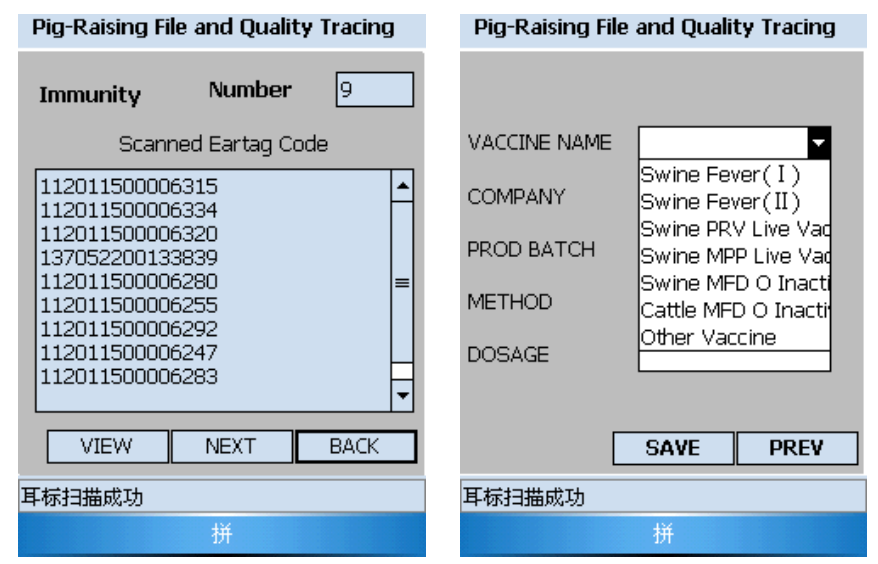

Fig. 3. Immunity events and data collecting for pigs 


\subsection{Collection and Transmission of Sampling Test Result by Official Supervisor}

Sampling inspection for residual toxic and harmful substance in body of pigs for sale is an important part to ensure pork quality safety. In general, official supervisors assigned by animal epidemic prevention and supervision department are in charge of sampling inspection in links of pig production, pig slaughter and pig distribution. At present, main inspective items are respectively Clenbuterol, sulfonamides and drugs residues. When accessing to data collection interface like Fig 4, users must pass limit confirmation and then can collect and transmit data. The input interface of inspection result in the right does not present until one or one batch ear tag code is inputted. Furthermore, the device system date on the mobile client is also uploaded as the sampling inspection date when the data is saved or uploaded.

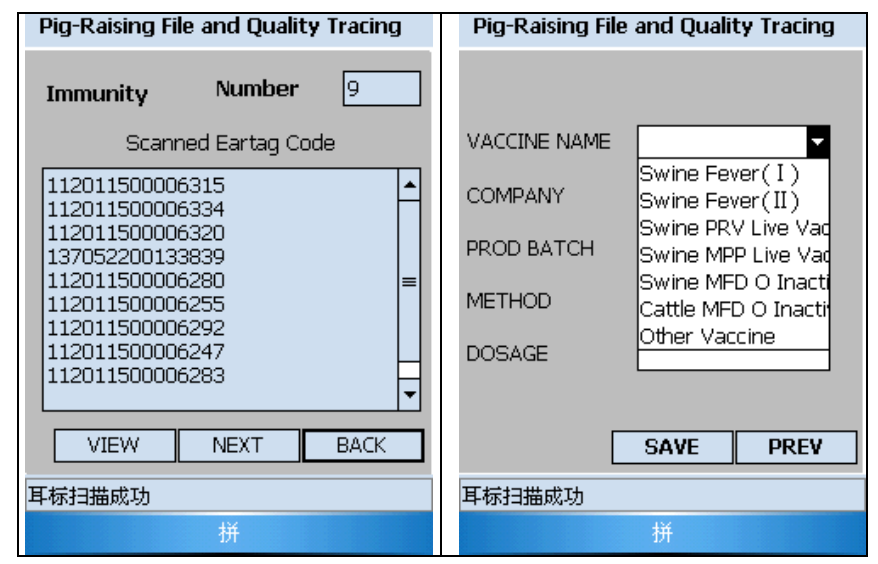

Fig. 4. Sampling inspection data collecting and submission for pigs
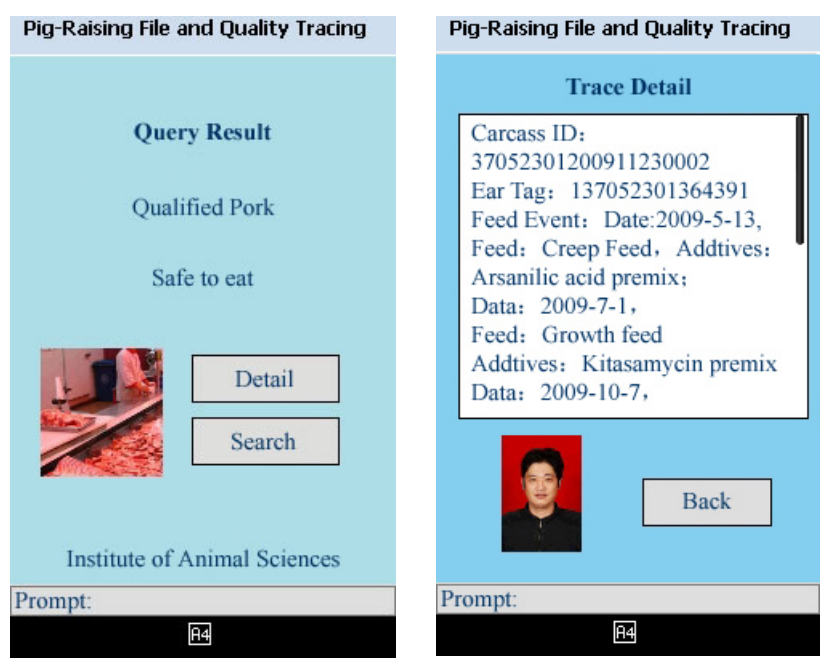

Fig. 5. Output of traceability inquiry results based on $3 \mathrm{G}$ system 


\subsection{Mobile Inquiry of Carved Pork}

As shown in Fig 5, by tracing model running on PDA, input 20-digit traceability code on the package ("37052301200912300002") and then receive the inquiry result. Regarding to $3 \mathrm{G}$ communication ability, the image transmission function is designed in the systematic inquiry interface, for example, sale image, official supervisor's image. More detail information also includes different inputs information.

\section{Discussion}

China is a big pig producing country, the number of pigs for sale reaches up to 640 million in 2009, pork production up to 48890 thousand tons, both rank the first in the world[13]. But for pig production mode, both large sized commercial production and small scale backyard production will exist in a rather long period. How to build effect pork quality traceability system from pig production to consumer dinning-table is heavy responsibility for consumers' right and food safety despite of a difficult task. Therefore, exploring different modes of tracking and tracing technology solution of pork production for different requirement environments should prepare for a rainy day.

Normally, because producing number in large-scale commercial farms is big, their production and management are also standard, hardware and software in the information technology application is better than small-size farms and backyard farmers, pig-raising files data in raising process is collected by computer record and internet transmit system, batch data treatment is able to be accomplished[12]. Nevertheless, if there is the communication signal of GPRS or $3 \mathrm{G}$ within farm, the mobile data collection system is able to be used for recording part key data and modifying data in the center database by farmer technician or area official vet, especially fro sampling inspection information for pigs raised or for sale. In fact, the raising files for commercial farmers is conducted by farmer technicians and supervised by area official vet at present. The mobile system provides a mobile supervision means for supervisors.

Next, for free-range pig-raising farmers, constructing computer data recording and internet transmit system is not practical, so the mobile data collection solution is improved from that of 2009 based on GPRS technology [14]. Free-range farmer raising files on the remote server can be established for certain quality farmers with proper training and area official vet's help. Obviously, establishing pig-raising electronic files by this system is simpler than that based on computer, without warning function for feed additives and veterinary drugs' withdrawal period. But, it can meet general traceability requirement of consumers.

For the end product traceability, traceability inquiry based on $3 \mathrm{G}$ has obvious advantages comparing to that on GPRS technology developed by Xiong (2009), this study introduces image's inquiry and view (Fig 4). At present, although just trying to display supervisor and sale scene pictures, as supervision ticketing in deferent traceability points are put into effect in the future, they are directly viewed in relative links, especially for ticketing of illegal drugs in order to meet traceability right for 
high-grade consumers. Obviously, all these need 3G technology. With the rapid development of $3 \mathrm{G}$ technology, continuously increasing effective area and deducing charges, $3 \mathrm{G}$ technology application of the mobile traceability inquires will be more and more.

\section{Conclusion}

Tracking and traceability for the whole production process of pig and pork products is a focused issue widely concerned by governments at all levels and consumers at present and in a quite long time period and is also a test of government ability for people. This study showed that using smart PDA or phone, 3G wireless wide band network communication technology as well with internet, provide a solution of Chinese pig-raising information in the process of pig production, which includes mobile collection and transmit solution for farm manager and pig individual ID, main inputs in pig production, multimedia traceability solution such as that of image and text based on 3G. The developed system has been applied in Tianjin pork quality traceability network platform and application effects achieve the systematic design goal. The study is supplement for constructing pig-raising electronic files in commercial farms and may be a whole solution for free-range pig-raising farmers and can meet for high level consumers' right. As the rapid development of TD-SCDMA network service and decrease of service fee, data tracking and quality traceability in the whole pig production based on $3 \mathrm{G}$ technologies will be vast potential for future development.

Acknowledgements. Funding were provided by the national high technology research and development program of China (863 Program) (2006AA10Z266), Tianjin municipal science \& technology Innovation fund (06FZZDNC0100) and the national science \& technology program (2009ZX03001-019).

\section{References}

1. Lu, C.H., Wang, C.J., Hu, Y.N.: Animals and their Products Identification Technologies as well as Traceability Management, pp. 46-47. Chinese Agricultural Science \& Technology Press, Beijing (2007) (in Chinese)

2. CCTV.: Special View: Clenbuterol pork into Shuanghui (2011), http: //stock.jrj.com.cn/2011/03/1618499472023-1.shtml (in Chinese)

3. http://www. foodsafetynetwork.ca/aspx/public/ publication_detail.aspx?id=80: foodTraceability (2011)

4. U.S. Food and Drug Administration.: FDA Food Protection Plan six-month summary (2008). Retrieved from, http: / /www. fda.gov/oc/initiatives / advance/food/progressreport.html (2010)

5. United States Department of Agriculture(USDA): Marketing and Regulatory Programs Animal and Plant Health Inspection Service. National Animal Identification System (NAIS)- Technical Supplement to Draft Program Standards, http: //animalid.aphis.usda.gov/nais 
6. Decree No 67 of the Ministry of Agriculture, China.: The administrative rule on identification and farming files of livestock and poultry (2006) (in Chinese), http: / /www.agri.gov.cn/blgg/t20060628_638621.htm

7. Decree No 525 of the State Council of China.: Administrative rule on pig slaughter (2010), http://www.gov.cn/zwgk/2008-05/30/content_1000067.htm (in Chinese)

8. Fan T.H.: Development study for wide wireless communication technology: Chinese high technology enterprises 5, 63-67 (2004) (in Chinese)

9. National Bureau of Statistics of China.: Administrative districts code for the People's Republic of China (2006) (in Chinese), http://www.stats.gov.cn/tjbz/xzqhdm/t20070411_402397928.htm

10. Fu, X., Qi, N., Xu, J.: Windows Mobile telephone application and development. Posts \& Telecom Press, Beijing (2005) (in Chinese)

11. Luan, C.H., Wang, M.: The design and study of the embedded internet based on GPRS. Microcomputer Information 17(22), 94-96 (2006) (in Chinese)

12. Xiong, B.H., Lin, Z.H.: A Solution on Pork Quality Safety Production Traceability from Farm to Dining Table-Taking Tianjin City as an Example. Agricultural Sciences in China 42(1), 230-237 (2009) (in Chinese)

13. Gao, H.B.: Animal almanac of China. China Agriculture Press, Beijing (2008) (in Chinese)

14. Xiong, B.H., Fu, R.T., Lin, Z.H.: Identification of Swine Individuals and Construction of Traceability System under Free-range Pig-rearing System. Transactions of the CSAE 25(3), 98-102 (2009) (in Chinese) 